\title{
Experimental Determination of Chloride Penetration in Concrete with Real Cracks
}

\author{
C. Sosdean, D. Gubencu, G. De Schutter and L. Marsavina
}

\begin{abstract}
It is well known that the presence of cracks in reinforced concrete structures in aggressive environments accelerates rebar corrosion. The influence of real cracks in concrete structures on the penetration of chlorides and the resulting service life is being investigated in this study. Investigations were carried on at the Magnel Laboratory for Concrete Research of Ghent University, Belgium within a bilateral agreement with University Politehnica Timisoara, Romania. Non-steady state migration tests were realized according to NT BUILD 492, using an electrical field and real cracks in order to determine the chloride profile. Samples with different crack patterns, obtained by drilling from a reinforced concrete slab exposed to a simulated accidental failure of the central support and subsequent vertical loading until collapse, were used in the study in order to provide a more realistic image of the geometry of the cracks. The crack widths were measured using an optical microscope. The chloride penetration depth was measured with a colorimetric method on each specimen and the non-steady state diffusion coefficients were determined. For evaluating the parameters which have the most influence on chloride migration on the samples used in this experiment, a two-level factorial experiment was designed and carried out in the early stage. Afterwards, using a higher number of samples, the influence of the existence of cracks and also the influence of crack widths on chloride penetration was studied by means of other statistical procedures: comparison of two means, one-way ANOVA. The results obtained provide a better understanding of the diffusion process when dealing with concrete structures with real crack.
\end{abstract}

C. Sosdean $(\bowtie) \cdot$ D. Gubencu · L. Marsavina

Department Strength of Materials, University of Timisoara,

Blvd. M. Viteazu, No. 1, 300222 Timisoara, Romania

e-mail: corina.sosdean@yahoo.com

G. De Schutter

Magnel Laboratory for Concrete Research, Department of Structural Engineering,

Ghent University, Technologiepark-Zwijnaarde 904, B-9052 Ghent, Belgium

(C) Springer International Publishing Switzerland 2017

G. Pluvinage and L. Milovic (eds.), Fracture at all Scales,

Lecture Notes in Mechanical Engineering, DOI 10.1007/978-3-319-32634-4_10 


\section{Introduction}

Even though significant studies were performed in the last years in order to predict durability of concrete structures, chloride induced corrosion in reinforced concrete structures remains one of the major challenges. Due to the fact that most reinforced concrete structures are cracked either due to extreme loading, aggressive environment or poor workmanship during execution, it is very important to have a better understanding of chloride diffusivity in cracked concrete.

Researchers used a variety of programs to create cracks in undamaged concrete. Based on the crack preparation method, the reported experimental studies can be divided into two groups: destructive methods and non-destructive methods. The methods from the first category adopt different mechanical loading techniques to prepare cracks, such as: wedge splitting test [21], three or four-point bending test [27], Brazillian splitting test [2] and expansive core method [9]. Non-destructive methods used to generate cracks in concrete include studies based on the positioning and removal of thin copper sheets before final setting of concrete $[3,13]$ or inducing a crack by saw-cutting concrete cylinders longitudinally [19].

Real cracks in concrete have a complex 3D geometry and their influence on transport and degradation mechanisms is not straightforward, therefore very limited investigation of the influence of chloride diffusion on samples with real cracks has been conducted [22].

Due to the fact that it is difficult to evaluate the crack effect on the chloride diffusion characteristics, many applications using probabilistic approaches have been generally limited to the sound concrete without considering crack effect. Still, some researchers developed parametric studies of service life in cracked concrete, in order to determine the time to durability failure (time to corrosion). Kwon et al. [10] considered the cover depth and time-exposure parameter as design factors with varying values. Full parametric studies of the influence of crack width, roughness and the interval of drying-wetting cycles on the chloride profiles at cracked zone were developed by Ye et al. [26].

In present work, a study on the influence of cracks and crack widths in reinforced concrete structures with real cracks subjected to chloride ingress is presented.

Even though the behaviour of many natural phenomena was described by means of mathematical and statistical models, when referring to civil engineering and especially for the analysis of chloride penetration, few experimental data can be found in literature $[12,15]$. 


\section{Experimental Program}

\subsection{Details of Specimen}

In this research four kinds of samples have been used: samples without cracks and without rebars (S) (a); samples with cracks and without rebars (SC) (b); samples without cracks and with rebars (SR) (c) and samples with cracks and with rebars (SCR) (d), as it can be observed in Fig. 1, where a representative sample from each group is presented.

In order to obtain samples with real cracks, cylinders with $100 \mathrm{~mm}$ diameter and $50 \mathrm{~mm}$ thickness were drilled from a RC slab of $140 \mathrm{~mm}$ thickness and $1800 \mathrm{~mm}$ wide with the total length of $14.30 \mathrm{~m}$. This slab was exposed to failure of the central support and subsequent vertical loading which generated cracking and finally its collapse. As noticed, the cracks go all the way to the specimens and that is why the crack depth is not being considered in this research.

A concrete class $\mathrm{C} 30 / 37$ with a maximum size of $14 \mathrm{~mm}$ of the coarse aggregate was used in order to manufacture the slab. The test set-up and the results for the experimental large-scale test are described in detail in $[6,8]$.

For the investigation of the influence of different parameters on chloride diffusion, in this study, concrete samples with or without rebars, having different crack widths were used.

Fig. 1 Drilled sample categories [22]. a Sample type $\mathrm{S}$, b sample type $\mathrm{SC}$, c sample type SR, $\mathbf{d}$ sample type SCR
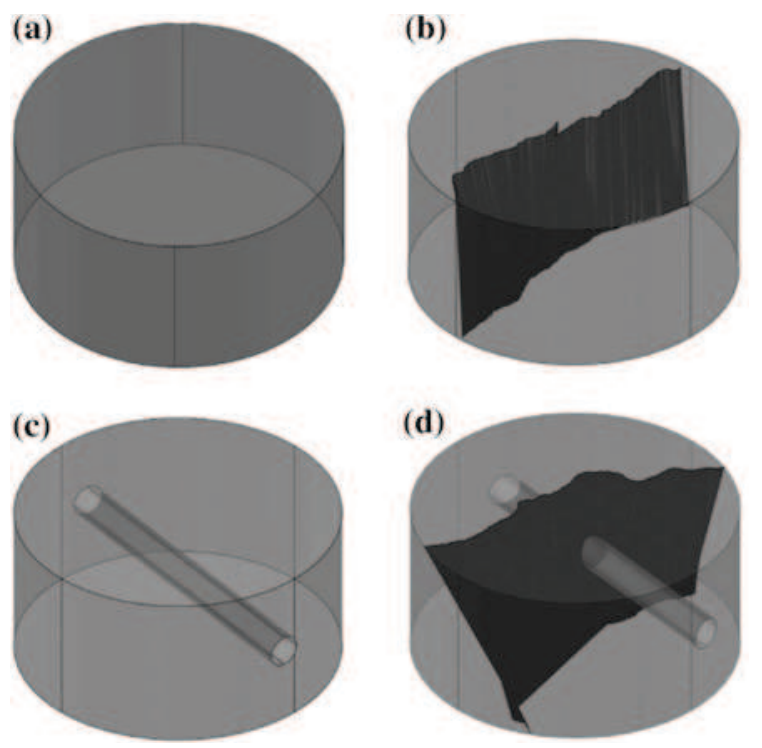


\subsection{Testing Method}

A non-steady state migration test was performed on the obtained concrete samples, according to NT BUILD 492 [16]. Before testing, the samples were placed in a vacuum container for vacuum treatment for $3 \mathrm{~h}$ to a pressure in the range of 1050 mbar; afterwards with the vacuum pump still running, the container was filled with saturated $\mathrm{Ca}(\mathrm{OH})_{2}$ solution so as to immerse all specimens which was maintained for a further hour before allowing air to re-enter the container. The specimens were kept in the solution for $18 \pm 2 \mathrm{~h}$.

Afterwards, the samples were placed in the reservoir and an external electrical potential of 30 and $35 \mathrm{~V}$ was applied on the samples for $24 \mathrm{~h}$, forcing the chloride ions from the $10 \% \mathrm{NaCl}$ solution to migrate into the specimens.

\subsection{Penetration Depth}

After the test, the samples were split and sprayed with $0.01 \mathrm{~N} \mathrm{AgNO}_{3}$ solution and by using the colorimetric method [17] the chloride penetration profile was determined. The mean penetration profiles were determined after cutting the sample perpendicular to the crack path and by measuring the chloride front on each of them. It must be mentioned that samples type $S$ were split in two, while samples type SR, SC and SCR were cut in 6 parts each perpendicular to the crack. A schematic representation of the procedure is presented in Fig. 2 for sample type $\mathrm{SC}$.

For samples type SC and SCR, the average chloride depth $\left(x_{d}\right)$ and the chloride depth near the crack $\left(x_{c}\right)$ were determined. For sample type $\mathrm{S}$, only $x_{d}$ was determined, while for sample type SR both $x_{d}$ and $x_{c}$ were determined. A schematic representation of the chloride depths measurement in the middle of the sample is presented in Fig. 3.

Fig. 2 Sample preparation for measuring the chloride front [22]

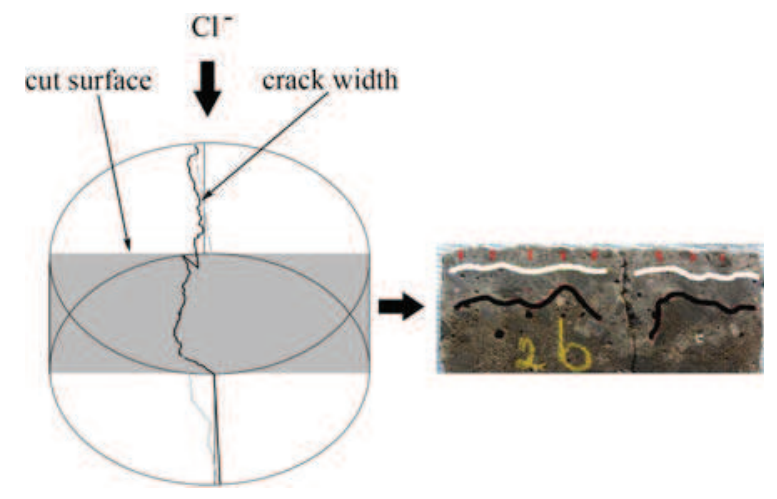


Fig. 3 Chloride front measurement in the middle of the sample

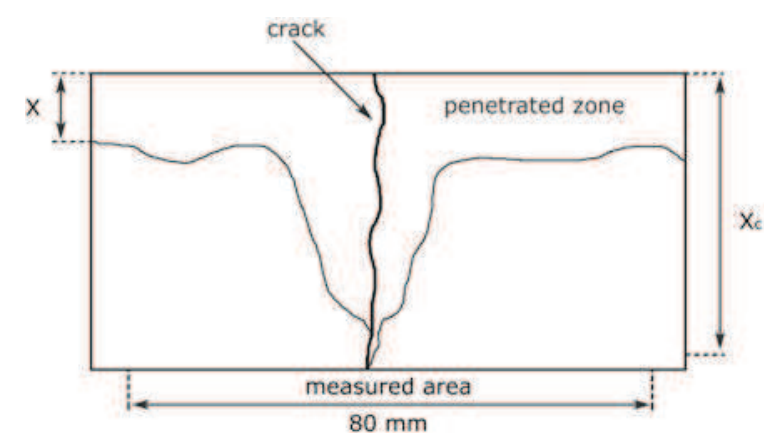

Based on the chloride penetration depth the chloride migration coefficient $\left(D_{n s s m}\right)$ can be calculated according to Eq. 1:

$$
D_{n s s m}=\frac{R T}{z \cdot F E} \cdot \frac{x_{d}-\alpha \sqrt{x_{d}}}{t}
$$

where

$$
\begin{gathered}
E=\frac{U-2}{L} \\
\alpha=2 \sqrt{\frac{R T}{z F E} \cdot \operatorname{erf}^{-1}\left(1-\frac{2 c_{d}}{c_{0}}\right)}
\end{gathered}
$$

$C_{d} \quad$ chloride concentration at which the color changes $(=0.07 \mathrm{~N})$

$C_{0} \quad$ chloride concentration in the cathodic solution (=2 N)

$e f^{-1}$ inverse of error function

$F \quad$ Faraday constant $\left(=9.648 \times 10^{4} \mathrm{~J} /(\mathrm{V} \mathrm{Mol})\right)$

$L \quad$ thickness of the specimens (m)

$R \quad$ gas constant $(=8.314 \mathrm{~J} /(\mathrm{K} \mathrm{Mol}))$

$x_{d} \quad$ chloride penetration depth (m)

$t \quad$ test duration $(\mathrm{sec})$

$T$ average value of the initial and final temperatures in the anolyte solution (K)

$U \quad$ applied voltage $(\mathrm{V})$

$z \quad$ absolute value of ionic valence ( $=1$ for chloride)

Figure 4 shows the combined effect of crack width and rebar position on the diffusion coefficient. It can be easily seen that the migration coefficient increases with the existence of cracks; when increasing the crack width from 0 (Sample S) to $0.2 \mathrm{~mm}$ (Sample SC), the migration coefficient increases from $5.96 \times 10^{-12}$ to $8.87 \times 10^{-12} \mathrm{~m}^{2} / \mathrm{s}$. Also it can be observed that the existence of rebars "blocks" chloride diffusion, the migration coefficient decreases to $8.41 \times 10^{-12} \mathrm{~m}^{2} / \mathrm{s}$. It seems that a lower value of $7.91 \times 10-12 \mathrm{~m}^{2} / \mathrm{s}$ is registered for the sample containing both rebars and cracks. 


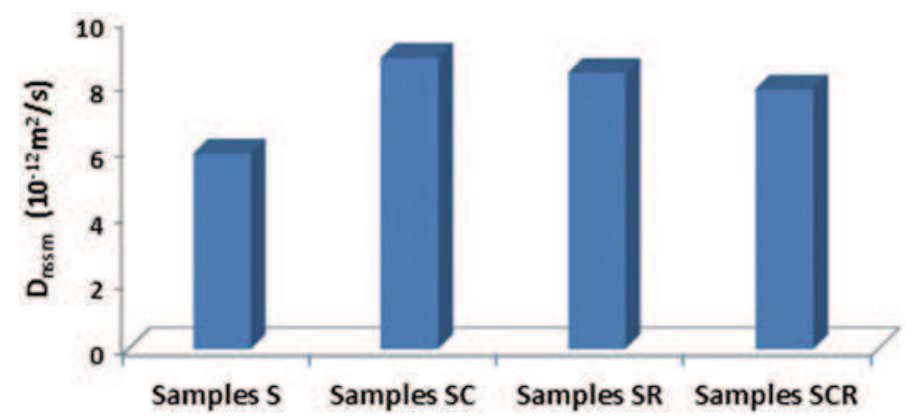

Fig. 4 Comparison of diffusion coefficient according to sample type [22]

It is important to mention that the values of the diffusion coefficient used in this study are mean values.

\section{Experimental Investigations and Discussions on Chloride Diffusivity in Non-steady State Migration Test}

\subsection{Early Stage: Experimental Modeling by Factorial Experiment}

The experimental data was analyzed using [24] software. In the first step of the experimental program, a limited number of samples were available. Moreover, certain parameters related to the crack pattern and the spatial orientation of the rebars couldn't be adjusted at rigorous set levels, but were randomly obtained. This is a consequence of the fact that the crack geometries were not induced artificially and are in fact real cracks obtained as a result of the collapsing of a real-scale slab.

Through the above presented results (Fig. 4), it can be observed that the presence of both cracks and rebars has an important influence on chloride ingress in cracked samples.

For the parametric study of chloride diffusion a two-level factorial experiment without randomization was designed and carried out in order to determine which of the following parameters: existence of cracks (Crack width 1) and existence of rebars (Rebar no), used in the experimental program, has the most important influence on chloride ingress in cracked samples subjected to non-steady state migration test. This type of experiment was considered to be the most appropriate in this stage of the research, due to the fact that with a minimum number of runs (available samples) an exploratory mathematical model of high precision can be obtained.

The values of the considered parameters, both coded and physical, for each sample together with measured values of the objective function-chloride penetration depth $\left(x_{d}\right)$ - are presented in Table 1. 
Table 1 Experimental matrix [22]

\begin{tabular}{l|l|l|l|l|l}
\hline \multirow{2}{*}{ Run no. } & \multicolumn{3}{l|}{ Levels of the influence factors } & Measured values \\
\cline { 2 - 6 } & $\mathrm{x}_{1} \equiv$ crack width_1 & $\mathrm{x}_{2} \equiv$ rebar No & $\mathrm{RN}$ & $\mathrm{y} \equiv x_{d}$ \\
\cline { 2 - 6 } & Coded & $(\mathrm{mm})$ & Coded & - & $(\mathrm{mm})$ \\
\hline 1 & -1 & 0 & -1 & 0 & 17.33 \\
\hline 2 & 1 & 0.2 & -1 & 0 & 22.48 \\
\hline 4 & -1 & 0 & 1 & 1 & 21.21 \\
\hline
\end{tabular}

Fig. 5 Standardized Pareto chart

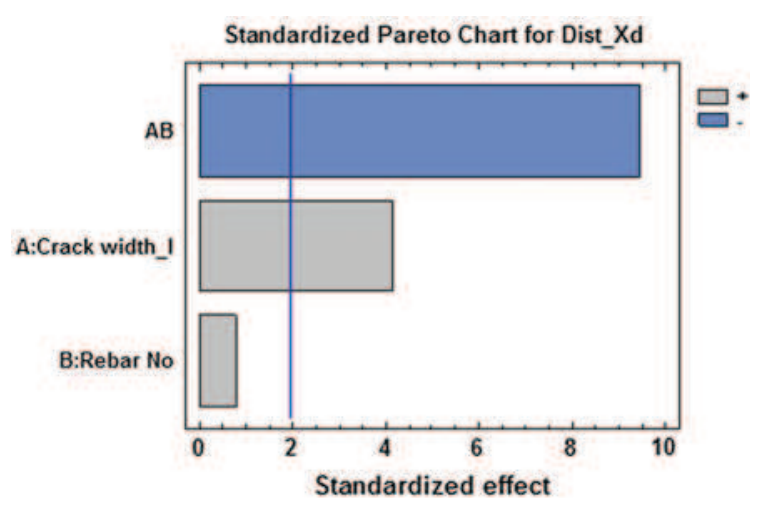

A standardized Pareto chart is presented in Fig. 5, which allows the hierarchy of both main effects and interaction effect on the response function.

As it can be observed, the interaction effect of crack width and rebar existence on chloride ingress is the most significant, followed by the existence of cracks. The effect of the rebar presence is not statistically significant on the chloride penetration depth $x_{d}$, having a magnitude comparable with the experimental error determined by performing 3 replicas in one experimental point. A possible explanation could be the fact that chlorides penetrate along the crack relatively fast up to the top of the crack (crack tip) [18], but their further propagation is being "blocked" by the existence of rebars. According to [25], when a crack in concrete intersects the steel reinforcing bar, it allows easy ingress of chloride ions, oxygen and water to the steel surface, which results in a faster initiation of corrosion.

The Eq. (3) of the fitted model is presented for coded values of the considered factors:

$$
x_{d}=20.055+0.7851+0.15 \mathrm{RN}-1.791 \mathrm{RN}
$$

Due to the fact that it is not possible to validate the model based on the different values of crack widths and, in addition, the experimental error was determined only for one experimental point located at the boundary of the multifactorial space, the practical applicability of the presented model could be limited.

Moreover, it is possible that different parameters, such as: crack existence, rebar presence, different crack widths, might influence chloride penetration in concrete 
and, consequently, have a significant importance in the determination of the migration coefficient. Therefore, a statistical analysis of the chloride penetration data was performed, using different methods: the comparison of means, the comparison of standard deviation and the analysis of variance (ANOVA). It must be noted that the results presented in this statistical analysis were previously presented as part of the research conducted in [23].

\subsection{Influence of the Existence of Cracks by Two Samples Comparison}

In order to determine whether the existence of cracks has a significant influence on the chloride penetration depth, the comparison of means method was used by comparing the means of the different test series using t-tests with a significance level of 0.05 .

It must be mentioned that in order to obtain an accurate result, a sufficient number of replicas is needed for each of the performed tests. As mentioned earlier, considering the fact that the crack geometries are in fact real cracks, the number of equal replicas for each test is almost impossible. Still, based on the existent information, the statistical analysis was realized in order to investigate the possible influence of the existence of cracks on chloride ingress.

Two-sample comparison tests based on the comparison of two means and the comparison of standard deviation methods were realized in order to determine the possible influence of the existence of cracks. These comparisons were made for different considered cases using the values of $x_{c}$ (chloride penetration depth near the crack) which was considered to be the most relevant when determining the influence of the existence of cracks on chloride penetration.

The two samples of data considered in this case are the values of $x_{c}$ obtained for reference samples and for samples with cracks having the top surface exposed. These values are presented in Table 2. It is important to mention that in the case of

Table 2 Penetration depth for samples with cracks

\begin{tabular}{l|l|l|l|l|l}
\hline \multirow{2}{*}{ Sample } & \multicolumn{2}{|l|}{$\begin{array}{l}\text { Chloride } \\
\text { penetration }\end{array}$} & \multirow{2}{*}{ Sample } & \multicolumn{2}{l}{$\begin{array}{l}\text { Chloride } \\
\text { penetration }\end{array}$} \\
\cline { 2 - 4 } \cline { 3 - 6 } & $\begin{array}{l}x_{d} \\
(\mathrm{~mm})\end{array}$ & $\begin{array}{l}x_{c} \\
(\mathrm{~mm})\end{array}$ & & $\begin{array}{l}x_{d} \\
(\mathrm{~mm})\end{array}$ & $x_{c}(\mathrm{~mm})$ \\
\hline $\mathrm{J}$ & 23.1 & 28.4 & 7 & 28.1 & 37.0 \\
\hline $\mathrm{K}$ & 28.0 & 36.8 & 13 & 25.9 & 30.9 \\
\hline $\mathrm{L}$ & 22.3 & 27.7 & 16 & 24.0 & 31.3 \\
\hline $\mathrm{M}$ & 23.9 & 26.4 & 25 & 21.1 & 31.9 \\
\hline $\mathrm{N}$ & 20.1 & 20.6 & A2 & 23.7 & $26.5 / 27.2$ \\
\hline 4 & 22.4 & 26.8 & B2 & 25.2 & 34.8 \\
\hline 6 & 15.2 & 28.4 & - & - & - \\
\hline & & & & & \\
\hline
\end{tabular}


Table 3 Penetration depth for reference samples type $\mathrm{S}$

\begin{tabular}{l|l|l|l}
\hline \multicolumn{2}{l|}{ Chloride penetration } & \multicolumn{2}{l}{ Chloride penetration } \\
\hline & $x_{d}(\mathrm{~mm})$ & & $x_{d}(\mathrm{~mm})$ \\
\hline Ref IV a & 21.4 & Ref IV b & 15.7 \\
\hline Ref V & 24.2 & Ref VII & 17.6 \\
\hline Ref VI & 26.3 & Ref VIII & 18.7 \\
\hline
\end{tabular}

Table 4 Summary statistics: depth $x_{c}$ by sample type

\begin{tabular}{l|l|l}
\hline & Sample type $=\mathrm{R}$ & Sample type $=\mathrm{S}$ \\
\hline Count & 9 & 13 \\
\hline Average & 20.8222 & 29.8077 \\
\hline Standard deviation & 3.56783 & 4.63797 \\
\hline Coeff. of variation & $17.1347 \%$ & $15.5596 \%$ \\
\hline Minimum & 15.7 & 20.6 \\
\hline Maximum & 26.3 & 37.0 \\
\hline Range & 10.6 & 16.4 \\
\hline Stnd. skewness & 0.191175 & -0.0674505 \\
\hline Stnd. kurtosis & -0.742232 & 0.0187035
\end{tabular}

reference samples, considering they have no cracks, the value of $x_{d}$ (average chloride penetration depth) was used (Table 3).

Sample 1, representing reference samples type $\mathrm{S}$ and SR, consists in 9 values ranging from 15.7 to 26.3 while sample 2 , representing samples with cracks type SC and SCR, consists in 13 values ranging from 20.6 to 37.0. These two samples of data are compared by means of various statistics and graphs and by running several tests in order to determine whether there are statistically significant differences between the two samples.

The sample characteristics are further presented in Table 4. The standardized skewness and standardized kurtosis can be used to determine whether the samples come from normal distributions. Values of these statistics outside the range of -2 to +2 indicate significant departures from normality. In this case, both standardized skewness and standardized kurtosis are within the range expected.

A t-test is run to compare the means of the two samples and it also constructs confidence intervals for each mean and also for the difference between the means. The test is used to investigate the null hypothesis about the difference between the means of the populations from which the two samples come. Considering that in the present test $\mathrm{t}=-4.88436$ and $P=0.0000897041$, meaning $P<0.05$ the null hypothesis is rejected in favor of the alternative. It means there is a statistically significant difference between the means of the two samples at the $95 \%$ confidence level.

The previously presented results assume that the variances of the two samples are equal. These assumptions are made based on the results of an F-test to compare the standard deviations presented in Table 5.

An F-test is run to compare the variances of the two samples and it also constructs confidence intervals for each standard deviation and for the ratio of the 
Table 5 Comparison of standard deviations: depth $x_{c}$ by sample type for top surface exposed

\begin{tabular}{l|l|l}
\hline & Sample type $=\mathrm{R}$ & Sample type $=\mathrm{S}$ \\
\hline Standard deviation & 3.56783 & 4.63797 \\
\hline Variance & 12.7294 & 21.5108 \\
\hline Df & 8 & 12 \\
\hline
\end{tabular}

variances. The test is used to investigate the null hypothesis about the standard deviations of the populations from which the two samples come. Considering that in this test $\mathrm{F}=0.591771$ and $P=0.464524$, meaning $P>0.05$ and the ratio of the standard deviation equals 0.591771 , the null hypothesis cannot be rejected. As a result there is not a statistically significant difference between the standard deviations of the two samples at the $95 \%$ confidence level.

The conclusion of this two-sample comparison test is that there is a statistically significant difference between the $\mathrm{x}_{\mathrm{c}}$ values of the compared two samples, meaning that, at $95 \%$ confidence level, the chloride penetration depth is influenced by the existence of cracks.

\subsection{Influence of Crack Widths by One-Way ANOVA}

For determining the influence of different crack widths, on the chloride penetration depth, respectively on the diffusion coefficient, one-way ANOVA analysis were performed with a level of significance of 0.05 .

One-way ANOVA tests were performed in order to determine the possible influence of the crack width on $D_{c}$ (diffusion coefficient measured near the crack). This procedure performs a one-way analysis of variance for diffusion coefficient $D_{c}$ considering the average crack width presented in Table 6.

Various tests and graphs are constructed to compare the mean values of $D_{c}$ for the considered 16 cores type SC and SCR with 4 different levels of crack width. The result characteristics of the one-way ANOVA are further presented in Table 7. The ANOVA table decomposes the variance of $D_{c}$ into two components: a between-group component, which measures the variability amongst $D_{c}$ determined

Table 6 Crack widths in samples

\begin{tabular}{|c|c|c|c|c|c|c|c|}
\hline \multirow[t]{2}{*}{ Sample } & \multicolumn{3}{|c|}{ Crack opening $(\mu \mathrm{m})$} & \multirow[t]{2}{*}{ Sample } & \multicolumn{3}{|c|}{ Crack opening $(\mu \mathrm{m})$} \\
\hline & Top & Bottom & Average & & Top & Bottom & Average \\
\hline $\mathrm{J}$ & 187 & 442 & 314 & 7 & 169 & 68 & 119 \\
\hline K & 190 & 396 & 293 & 13 & 164 & 131 & 148 \\
\hline $\mathrm{L}$ & 269 & 359 & 314 & 16 & 130 & 108 & 119 \\
\hline $\mathrm{M}$ & 211 & 389 & 300 & 25 & 141 & 66 & 104 \\
\hline $\mathrm{N}$ & 338 & 232 & 285 & A2 & 173 & 148 & 161 \\
\hline 4 & 143 & 79 & 111 & $\mathrm{~B} 2$ & 93 & 155 & 124 \\
\hline 6 & 154 & 160 & 157 & - & - & - & - \\
\hline
\end{tabular}


Table 7 Summary statistics: diffusion

\begin{tabular}{l|l|r|l|l|l}
\hline Source & Sum of squares & Df & Mean square & F-ratio & $P$-value \\
\hline Between groups & 51.4673 & 3 & $\mathrm{MS}_{\text {level }}=17.1558$ & 5.28 & 0.0149 \\
\hline Within groups (error) & 39.0063 & 12 & $\mathrm{MS}_{\mathrm{E}}=3.25052$ & & \\
\hline Total (corr.) & 90.4736 & 15 & & & \\
\hline
\end{tabular}

Table 8 Table of means for Dc by crack width with $95 \%$ LSD intervals

\begin{tabular}{l|l|l|l|l|l}
\hline \multicolumn{7}{l}{ Stnd. error } \\
\hline Level & Count & Mean & (pooled s) & Lower limit & Upper limit \\
\hline 0 & 3 & 8.38333 & 1.04092 & 6.77964 & 9.98703 \\
\hline 0.1 & 5 & 13.47 & 0.80629 & 12.2278 & 14.7122 \\
\hline 0.15 & 3 & 12.7167 & 1.04092 & 11.113 & 14.3204 \\
\hline 0.3 & 5 & 11.994 & 0.80629 & 10.7518 & 13.2362 \\
\hline Total & 16 & 11.9137 & & & \\
\hline
\end{tabular}

for samples with different crack width and a within-group component, which measures the variability amongst $D_{c}$ determined for samples with the same crack width. The $\mathrm{F}$ ratio, which in this case $\mathrm{F}=5.27785$, is a ratio of the between-group mean square $\left(\mathrm{MS}_{\text {level }}\right)$ to the within-group estimate $\left(\mathrm{MS}_{\mathrm{E}}\right)$. Since the calculated probability, $P=0.0149$, computed for the determined $\mathrm{F}$ and for the considered degrees of freedom (Df) is less than the pre-chosen significance level 0.05 $(P<0.05)$ there is a statistically significant difference between the mean $D_{c}$ from one level of crack width to another at the $95 \%$ confidence level [14].

The table of means for $D_{c}$ by crack width is further presented in Table 8. Also, the table shows the standard error of each mean which is a measure of its sampling variability. The standard error is formed by dividing the pooled standard deviation by the square root of the number of observations at each level. The table also displays an interval around each mean. The intervals are based on Fisher's least significant difference (LSD) procedure and are constructed in such a way that if two means are the same, the intervals will overlap $95 \%$ of the time. This does not imply that every mean is significantly different from every other mean.

To determine which means are significantly different from which others the Multiple Range Test is carried on. Table 9 presents which means are significantly different from which others by using a multiple comparison procedure.

The bottom half of the output shows the estimated difference between each pair of means. An asterisk has been placed next to 3 pairs, indicating that these pairs show statistically significant differences at the $95 \%$ confidence level.

Figure 6 presents the interval plots at $95 \%$ confidence of diffusion coefficient $D_{c}$ for each crack width. It can be observed that there is a statistical significant difference between the values obtained for the reference samples and the values obtained for samples with cracks, but no statistical significant difference is between the different considered widths. 
Table 9 Multiple range tests results for $95 \%$ LSD-Dc by crack width

Fig. 6 Interval plot $(95 \%$ confidence) of $D_{c}$ for crack width [22]

\begin{tabular}{l|l|l|l|l}
\hline Level & Count & Mean & Homogeneous groups \\
\hline 0 & 3 & 8.38333 & X & \\
\hline 0.3 & 5 & 11.994 & X & \\
\hline 0.15 & 3 & 12.7167 & X & \\
\hline 0.1 & 5 & 13.47 & X \\
\hline Contrast & Sig. & Difference & \pm Limits \\
\hline $0-0.1$ & $*$ & -5.08667 & 2.86878 \\
\hline $0-0.15$ & $*$ & -4.33333 & 3.20739 \\
\hline $0-0.3$ & $*$ & -3.61067 & 2.86878 \\
\hline $0.1-0.15$ & \multicolumn{5}{|l|}{0.753333} & 2.86878 \\
\hline $0.1-0.3$ & \multicolumn{5}{|c}{0.476} & 2.48443 \\
\hline $0.15-0.3$ & \multicolumn{5}{|c}{0.8667} \\
\hline
\end{tabular}

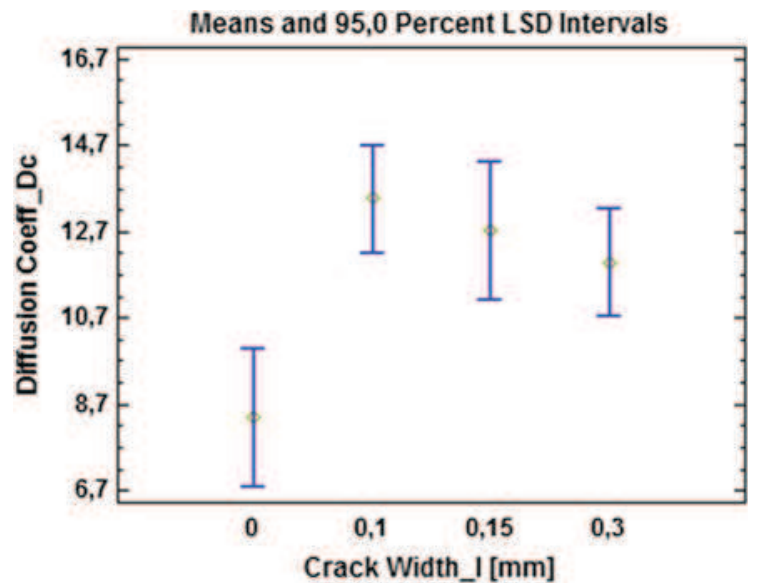

\section{Conclusions}

The effects hierarchy and the experimental model achieved in the early stage of investigation show that even if the presence of cracks led to the enlargement of the chloride penetration depth, it seems that the combined effect of both crack width and rebar existence determine the decrease of this objective function. In that case, the rebar presence obstructs the diffusion process and makes it more difficult.

The possible influence of the presence of cracks was further investigated, by the comparison of means method at a $95 \%$ confidence interval, in order to eliminate its influence. The chloride penetration depth near the crack $\left(x_{c}\right)$ is influenced by the existence of cracks when having the top surface exposed and taking into consideration all sample types ( $\mathrm{S}$ - samples without cracks and rebars, $\mathrm{SC}$ - samples with cracks and without rebars, SR - samples without cracks and with rebars and SCRsamples with cracks and rebars). 
Next, the possible influence of the crack widths on the available samples was investigated by performing a one-way ANOVA test at a $95 \%$ confidence interval and considering the average crack width, as previously presented in Table 6, respectively the values of $D_{c}$ (migration coefficient near the crack) computed considering the average crack widths of: $0.1 ; 0.15$ and 0.3 . It seems there is no statistical significant difference between the values of $D_{c}$ for the considered crack widths.

It is generally recognized that the existence of cracks provide fast transport routes for chloride. However, crack width can be considered to be one of the most controverted parameters that can influence chloride ingress.

Even though there are different codes prescribing an allowable crack width ranging from 0.05 to $0.3 \mathrm{~mm}[1,4,5]$, the influence of crack width on concrete properties is still under debate. Gérard and Marchand [7] show that the steady state migration coefficients of concrete with different crack widths are one order of magnitude higher than for uncracked concrete. While some researchers [11] suggest the dependence between chloride profiles and crack width, Rodriguez and Hooton [20] suggests that chloride diffusion in concrete is independent of the crack width since cracks act as free concrete surfaces and greatly promote chloride ingress and Marsavina et al. [13] concludes that the influence of crack on chloride penetration is still not clear and requires further research.

Acknowledgments This work was done in the framework of Bilateral Scientific Agreement between Ghent University, Belgium and Politehnica University of Timisoara, Romania. Also, the financial support by the Special Research Fund (BOF) of Ghent University is gratefully acknowledged.

\section{References}

1. ACI Committee 224 (1999) Control of cracking in concrete structures (ACI 224R-90), ACI manual of concrete practice, part 3, ACI

2. Aldea CM et al (1999) Effect of cracking on water and chloride permeability of concrete. J Mater Civ Eng ASCE 11(3):181-187

3. Audenaert $\mathrm{K}$ et al (2009) Influence of cracks on the service life of concrete structures in a marine environment. Key Eng Mater 339:153-160

4. British Standards Institution (1997) BS 8110: part 1. BSI, London

5. British Standards Institution (1992) ENV 1991-1-1. BSI, London

6. Caspeele R et al (2013) Structural reliability of concrete slabs considering tensile membrane action. In: Safety, reliability and risk analysis: beyond the horizon, proceedings, pp 2713-2720

7. Gérard B, Marchand J (2000) Influence of cracking on the diffusion properties of cement-based materials: part I: influence of continuous cracks on the steady-state regime. Cem Concr Res 30(1):37-43

8. Gouverneur D et al (2013) Experimental investigation of the load-displacement behavior under catenary action in a restrained reinforced concrete slab strip. Eng Struct 49:1007-1016

9. Ismail M et al (2004) Effect of crack opening on the local diffusion of chloride in inert materials. Cem Concr Res 34(4):711-716 
10. Kwon SJ et al (2009) Service life prediction of concrete wharves with early-aged crack: probabilistic approach for chloride diffusion. Struct Saf 31:75-83

11. Li CQ (2001) Initiation of chloride-induced reinforcement corrosion in concrete structural members-experimentation. ACI Struct J 98(4):502-510

12. Maes M, De Belie N (2013) Resistance of cracked concrete to chloride attack. In: 3rd international conference on sustainable construction materials and technologies. Kyoto Research Park, pp 1-10

13. Marsavina L et al (2009) Experimental and numerical determination of the chloride penetration in cracked concrete. Constr Build Mater 23(1):264-274

14. Montgomery DC, Runger GC (2010) Applied statistics and probability for engineers. Wiley, Hoboken

15. Nieves-Mendoza D, Gaona-Tiburcio C, Hervert-Zamora HL, Almeraya-Calderón F (2012) Statistical analysis of factors influencing corrosion in concrete structures. Int J Electrochem Sci 7:5495-5509

16. NT BUILD 492 (1999) Concrete, mortar and cement-based repair materials: chloride migration coefficient from non-steady-state migration experiments. NORDTEST

17. Otsuki $\mathrm{N}$ et al (1992) Evaluation of $\mathrm{AgNO}_{3}$ solution spray method for measurement of chloride penetration into hardened cementations matrix materials. ACI Mater J 89(6):587-592

18. Ožbolt J, Balabanic G, Periškić, Kušter M (2010) Modelling the effect of damage on transport processes in concrete. Constr Build Mater 24(9):1638-1648

19. Pour-Ghaz M et al (2009) Numerical and experimental assessment of unsaturated fluid transport in saw-cut (Notched) concrete elements. ACI Special Publication SP266-06, vol 266, pp 73-86

20. Rodriguez OG, Hooton RD (2003) Influence of cracks on chloride ingress into concrete. ACI Mater J 100(2):102-126

21. Schlangen E et al (2007) Measurement of chloride ingress in cracked concrete. In: Audenaert K, Marsavina L, De Schutter G (eds) International RILEM workshop on transport mechanisms in cracked concrete. Acco, Leuven, pp 19-25

22. Sosdean $C$ et al (2014) Influence of real cracks on chloride diffusion. In: Kytyr D (ed) YSESM proceedings of XIIIth youth symposium on experimental solid mechanics. CTUP, CZ, pp $16-120$

23. Sosdean C (2015) Experimental and numerical investigations of the influence of cracks on mass diffusion in mortar and concrete (PhD thesis), Politehnica University of Timisoara, Timisoara, Romania

24. Statgraphics (1997). Statgraphics plus, version 3.0

25. Subramaniam KV, Bi M (2010) Investigation of steel corrosion in cracked concrete: evaluation of macrocell and microcell rates using Tafel polarization response. Corros Sci 52:2725-2735

26. Ye $\mathrm{H}$ et al (2012) Model of chloride penetration into cracked concrete subject to dryingwetting cycles. Constr Build Mater 36:259-269

27. Ye $\mathrm{H}$ et al (2013) Influence of cracking on chloride diffusivity and moisture influential depth in concrete subjected to simulated environmental conditions. Constr Build Mater 47:66-79 
Lecture Notes in Mechanical Engineering 
Lecture Notes in Mechanical Engineering (LNME) publishes the latest developments in Mechanical Engineering-quickly, informally and with high quality. Original research reported in proceedings and post-proceedings represents the core of LNME. Also considered for publication are monographs, contributed volumes and lecture notes of exceptionally high quality and interest. Volumes published in LNME embrace all aspects, subfields and new challenges of mechanical engineering. Topics in the series include:

- Engineering Design

- Machinery and Machine Elements

- Mechanical Structures and Stress Analysis

- Automotive Engineering

- Engine Technology

- Aerospace Technology and Astronautics

- Nanotechnology and Microengineering

- Control, Robotics, Mechatronics

- MEMS

- Theoretical and Applied Mechanics

- Dynamical Systems, Control

- Fluid Mechanics

- Engineering Thermodynamics, Heat and Mass Transfer

- Manufacturing

- Precision Engineering, Instrumentation, Measurement

- Materials Engineering

- Tribology and Surface Technology

More information about this series at http://www.springer.com/series/11236 
Guy Pluvinage $\cdot$ Ljubica Milovic

Editors

\section{Fracture at all Scales}

Springer 
Editors

Guy Pluvinage

LABPS

ENIM

Metz

France
Ljubica Milovic

Faculty of Technology and Metallurgy

University of Beograd

Beograd

Serbia

ISSN 2195-4356 ISSN 2195-4364 (electronic)

Lecture Notes in Mechanical Engineering

ISBN 978-3-319-32633-7

ISBN 978-3-319-32634-4 (eBook)

DOI 10.1007/978-3-319-32634-4

Library of Congress Control Number: 2016946303

(C) Springer International Publishing Switzerland 2017

This work is subject to copyright. All rights are reserved by the Publisher, whether the whole or part of the material is concerned, specifically the rights of translation, reprinting, reuse of illustrations, recitation, broadcasting, reproduction on microfilms or in any other physical way, and transmission or information storage and retrieval, electronic adaptation, computer software, or by similar or dissimilar methodology now known or hereafter developed.

The use of general descriptive names, registered names, trademarks, service marks, etc. in this publication does not imply, even in the absence of a specific statement, that such names are exempt from the relevant protective laws and regulations and therefore free for general use.

The publisher, the authors and the editors are safe to assume that the advice and information in this book are believed to be true and accurate at the date of publication. Neither the publisher nor the authors or the editors give a warranty, express or implied, with respect to the material contained herein or for any errors or omissions that may have been made.

Printed on acid-free paper

This Springer imprint is published by Springer Nature

The registered company is Springer International Publishing AG Switzerland 